\title{
Consideration of Size and Dimension in the Evaluation of Transfers during Convective Drying of Sweet Potato
}

\author{
Abdou-Salam Ganame, Kondia Honore Ouoba*, François Zougmore \\ Laboratoire des Matériaux et Environnement (LAME), Unité de Formation et de Recherche en Sciences Exactes et Appliquée \\ (UFR/SEA), Université de Ouaga I, Ouagadougou, Burkina Faso \\ Email: *ouobakahonore@yahoo.fr
}

How to cite this paper: Ganame, A.-S., Ouoba, K.H. and Zougmore, F. (2020) Consideration of Size and Dimension in the Evaluation of Transfers during Convective Drying of Sweet Potato. Journal of Analytical Sciences, Methods and Instrumentation, 10, 104-112.

https://doi.org/10.4236/jasmi.2020.104008

Received: October 16, 2020

Accepted: December 21, 2020

Published: December 24, 2020

Copyright $\odot 2020$ by author(s) and Scientific Research Publishing Inc. This work is licensed under the Creative Commons Attribution International License (CC BY 4.0).

http://creativecommons.org/licenses/by/4.0/

\begin{abstract}
This work is interested in solving the complex problem of understanding mass transfers in biological media. The contribution of the initial sample size is taken into account. Transfers are established more efficiently in small samples. Thus, from the first 50 minutes, the cubic sample at $1 \mathrm{~cm}$ stop is already at $50 \%$ while the sample at $4 \mathrm{~cm}$ edge is at about $90 \%$ of its initial water content. Likewise the shape is combined with the size. But it is revealed that if we fix similar characteristic dimensions, we can bypass the notion of initial shape. Thus the cubic samples $4 \mathrm{~cm}$ of edges. $4 \mathrm{~cm}$ diameter of spherical shape, $4 \mathrm{~cm}$ $\times 4 \mathrm{~cm}$ height-diameter cylindrical one, all dry identically.
\end{abstract}

\section{Keywords}

Mass Transfer, Size, Shape, Agri-Food Products

\section{Introduction}

The heat and mass transfer in biological structure is dictated by several parameters [1] [2] [3]. Several studies have highlighted the influences of environmental parameters such as temperature [4] [5], velocity [2], relative humidity [6] [7] of the air [8] [9] [10]. In addition to these parameters, there are also parameters related to the nature of the matter [11] [12]. Ouoba [13] has established that the internal structure of the product varies during drying and leads to changes in the behavior of the material regarding heat and masse transfers [8] [14] [15]. Ouoba et al. [16] have shown that the intrinsic properties of the product play a role on the quality of transfers during convective drying, using okra as a product with a complex macrostructure and also potato considered as a product with a homo- 
geneous structure. Ganame et al. [17] took the study further by using several products such as tomato, cucumber, zucchini and came to the same conclusion that the structure of the product dictates the law of transfers during its convective drying. Using samples of potatoes of various shapes and sizes, Ouoba et al. [13] [18] concluded that it is not possible to characterize the drying of a product without taking into account its shape and size. Ouoba [13] introduces the notion of characteristic dimension to bypass the notion of shape when evaluating the convective drying of agrifood products.

In this present work, we will look for the importance of taking into account the size and the initial shape of cubic, cylindrical and spherical sweet potato samples. We will particularly examine the contribution of the form factor defined by Ouoba [13] for these different samples, during their convective drying.

\section{Material and Methods}

\subsection{Sweet Potato}

In order to follow the evolution of the water content of the product, with regard to its size and shape, it is essential to take a product with a quasi-uniform macro-structure and which lends itself easily to cutting. Sweet potato is a product that has these criteria. In addition, we can easily cut fairly large samples from sweet potato, which may go to the size useful for our experiments.

Sweet potato was purchased at a local fruit market in Bobo-Dioulasso, Burkina Faso and transported to the laboratory. They were kept under slightly damp sand. This is the traditional method of preserving sweet potatoes in Burkina Faso. This method allows keeping the tuber fresh for a long period of time, up to more than 03 months. They are dug up washed, peeled and cut to the desired shape and size. For this present work, we kept the cubic, spherical and cylindrical shapes. The [WTF BINDER] oven is first set to a temperature of $80^{\circ} \mathrm{C}$. A balance [STRASTON $\pm 0.001 \mathrm{~g}$ ] is used to determine the mass of the samples. To establish the drying kinetics, the sample is removed from the oven at a fixed time interval, after a first rough test, its mass is measured and it is reintroduced into the oven. The measurement time is minimized [2] [13] so as not to disturb the mass and heat transfer processes already established in the sample [16].

The samples, once cut, are kept in a container filled with water; this is to avoid the establishment of transfers before their introduction into the dryer.

When thermal equilibrium is reached in the oven, the samples are removed from the water and then wiped using a blotting paper [2] [13] [19]. Thus, the residual water kept on the surface is eliminated.

They are therefore introduced into the oven where drying begins, just after having noted their respective mass.

\subsection{Experiment Process}

During the drying experiment, some precautions are taken in order to minimize the contribution of the other parameters on the evaluation of the importance of the size on the drying [20] [21] [22]. 
The study's opening time is as short as possible. It is in view of not disturbing too much the thermal balance pre-established within it [11] [18].

The time taken to collect the masses is reduced as much as possible. This is in order not to disturb the thermal equilibrium established in the materials [2] [17].

Samples are removed from the oven at pre-set time intervals. They are weighed for the determination of the mass at the instant $t$ of drying, $m[t]$.

\subsection{Data Processing}

The initial water content $X_{0}\left[\mathrm{Kg}_{w} / \mathrm{Kg}_{e}\right]$ of sweet potato is determined by taking the initial mass $m_{0}[g]$ of the sample. Then, the sample is introduced in an oven set at $70^{\circ} \mathrm{C}$ for 24 hours. The mass of the sample after the 24 hour stay is the mass of the solid skeleton, i.e. the mass of the sample without any trace of water. We will denote it $m_{s}[g]$. The initial water content is calculated by the following relation [3] [13] [23]:

$$
X_{0}=\frac{m_{w[0]}}{m_{s}}=\frac{m_{0}-m_{s}}{m_{s}}
$$

Establishing drying kinetics requires collecting the mass of the sample over time. At a given time $t$ from the mass $m(t)$ of the sample, we deduce the water content $X[t]$ of the sample by the relation [11] [13]:

$$
X[t]=\frac{m_{w}[t]}{m_{s}}=\frac{m[t]-m_{s}}{m_{s}}
$$

Then, we get the kinetics curve by plotting the relation $X(t)-t$

\section{Results and Discussions}

\subsection{Taking into Account the Size}

\subsubsection{Cubes of Edges 1, 2, 3 and $4 \mathrm{~cm}$}

Figure 1 compares the behavior of cubic samples of different dimensions, i.e. edges of $1,2,3$, and $4 \mathrm{~cm}$, subjected to convective drying at $80^{\circ} \mathrm{C}$.

For this cubic shape, the results show that size plays an important role in the process of water transfer into the product.

From the first 50 minutes, the small sample, i.e. the sample at $1 \mathrm{~cm}$ edge, is already at $50 \%$ of its initial water content. For the same duration, the largest sample, the sample at $4 \mathrm{~cm}$ edge is about $90 \%$ of its initial water content. The $2 \mathrm{~cm}$ and $3 \mathrm{~cm}$ edges of cubic samples are, respectively, at $65 \%$ and $80 \%$ of their initial water content.

At $250 \mathrm{~min}$ of drying time, the cube at $1 \mathrm{~cm}$ edge is almost dry. The large sample only lost half of its water content. The samples at $2 \mathrm{~cm}$ and $3 \mathrm{~cm}$ edges are at about $20 \%$ and $40 \%$ of their initial water content during this drying period, i.e. $250 \mathrm{~min}$.

These results reveal the importance of taking into account parameters such as dimension during the drying process of agro-food products, as suggested by Ouoba [19]. 


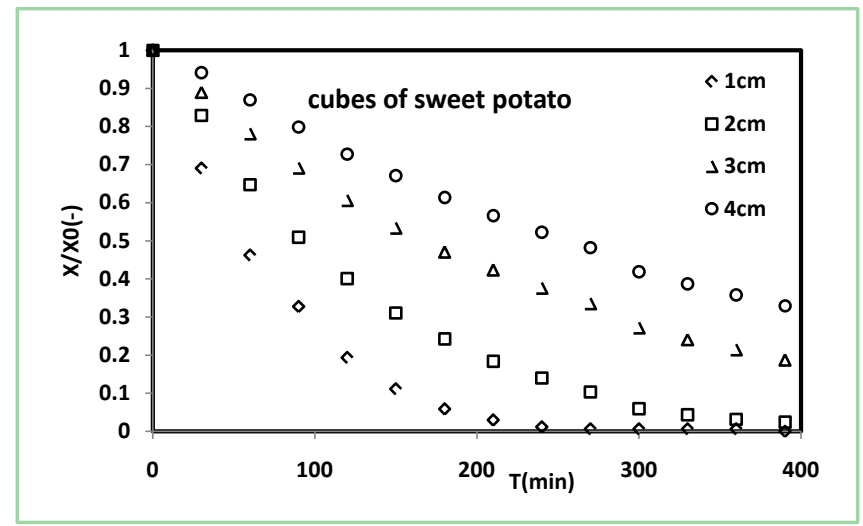

Figure 1. Influence of the initial dimension on convective drying, $\mathrm{T}=80^{\circ} \mathrm{C}$, cubes of sweet potatoes

It would therefore be advisable, for a dried product of uniform quality, to separate the cubic samples according to their sizes before their convective drying.

\subsubsection{Spheres, Diameters 1, 2, 3 and $4 \mathrm{~cm}$}

Figure 2 compares the behavior of spherical samples of different sizes, under convective drying at $80^{\circ} \mathrm{C}$. The spherical shaped samples used for this present case have diameters of 1,2,3 and $4 \mathrm{~cm}$.

For this spherical shape, the efficiency of the transfers is directly linked to the initial size of the sample.

From the first 50 minutes, the small sample, i.e. the $1 \mathrm{~cm}$ diameter sample is already at $55 \%$ of its initial water content. Meanwhile, the larger sample, the 4 $\mathrm{cm}$ diameter sample is about $85 \%$ of its original water content. spherical samples of $2 \mathrm{~cm}$ and $3 \mathrm{~cm}$ in diameter are, respectively, at $80 \%$ and $78 \%$ of their initial water content.

After a drying time of $280 \mathrm{~min}$, the $1 \mathrm{~cm}$ diameter sphere has reached its final water content. The large sample lost only $55 \%$ of its water content. The samples $2 \mathrm{~cm}$ and $3 \mathrm{~cm}$ in diameter are approximately $28 \%$ and $40 \%$ of their initial water content during this drying period, i.e. $280 \mathrm{~min}$.

For the spherical shape, the analysis of the results therefore proves that the initial dimension is an important parameter for the evaluation of the drying of sweet potato.

Optimizing the drying of cubic shapes requires separating or sorting the samples according to their initial size, if they have the spherical shape

\subsubsection{Cylinders Hxd: $1 \times 1,2 \times 2,3 \times 3$ et $4 \times 4 \mathrm{~cm}$}

Figure 3 compares the behavior of cylindrical samples of different dimensions, subjected to convective drying at $80^{\circ} \mathrm{C}$.

The samples used have a height-diameter dimension of $1 \mathrm{~cm} \times 1 \mathrm{~cm}, 2 \mathrm{~cm} \times 2$ $\mathrm{cm}, 3 \mathrm{~cm} \times 3 \mathrm{~cm}$ and $4 \mathrm{~cm} \times 4 \mathrm{~cm}$. For this cylindrical shape, the results show that the dimension plays an important role in the process of water transfer into the product. 


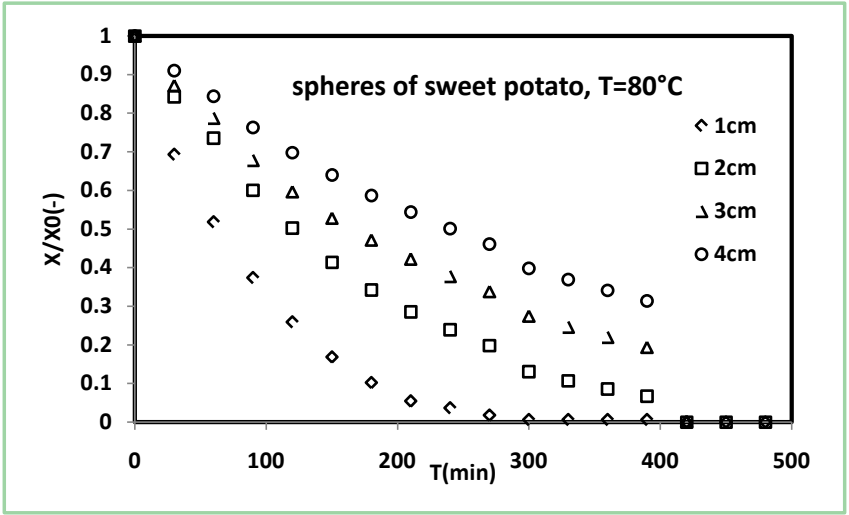

Figure 2. Influence of the initial dimension on convective drying, $\mathrm{T}=80^{\circ} \mathrm{C}$, sweet potato spheres.

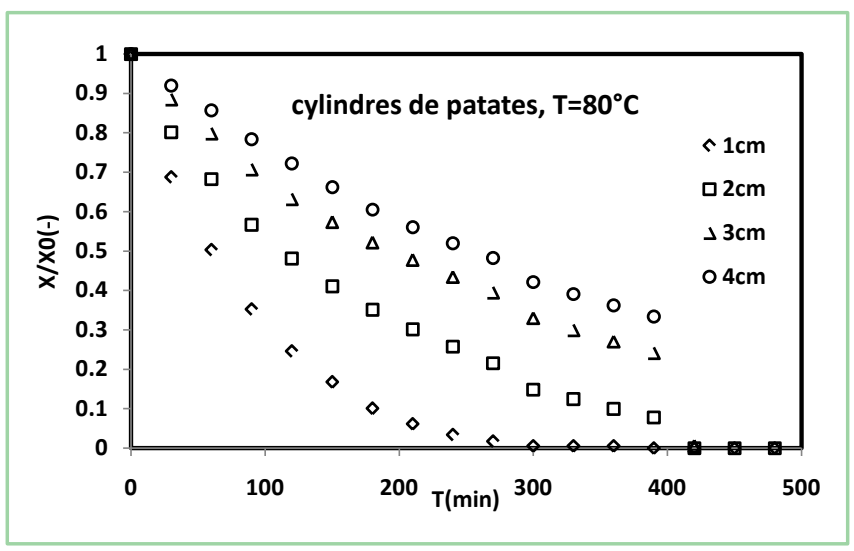

Figure 3. Influence of the initial dimension on convective drying, $\mathrm{T}=80^{\circ} \mathrm{C}$, cylinders of sweet potatoes.

The small sample, i.e. height-diameter of $1 \mathrm{~cm} \times 1 \mathrm{~cm}$, reached half of its initial water content in about the first 50 minutes.

For the same time, the larger sample, the $4 \mathrm{~cm} \times 4 \mathrm{~cm}$ height-diameter sample is about $88 \%$ of its initial water content. Cylindrical samples of $2 \mathrm{~cm} \times 2 \mathrm{~cm}$ and $3 \mathrm{~cm} \times 3 \mathrm{~cm}$ height-diameter are, respectively, $70 \%$ and $80 \%$ of their initial water content.

At 260 min of drying time, the $1 \mathrm{~cm} \times 1 \mathrm{~cm}$ height-diameter cylinder is almost dry. The large sample only lost half of its water content. The samples at $2 \mathrm{~cm} \times 2$ $\mathrm{cm}$ and $3 \mathrm{~cm} \times 3 \mathrm{~cm}$ height-diameter are at approximately $20 \%$ and $40 \%$ of their initial water content during this drying period, i.e. $260 \mathrm{~min}$.

These results show the importance of taking into account parameters such as size during the drying process of agro-food products.

It would therefore be, for a dry product of good quality, to separate the cylindrical samples according to their size before their convective drying.

\subsection{Taking into Account the Shape}

While it is established from the above that size is an important parameter in the appreciation of drying, it is also important to examine the role that shape plays 
in this process of drying agrifood products.

At the drying temperature of $80^{\circ} \mathrm{C}$, we examine, by Figure 4 , the behavior of samples of different shapes according to water transfers.
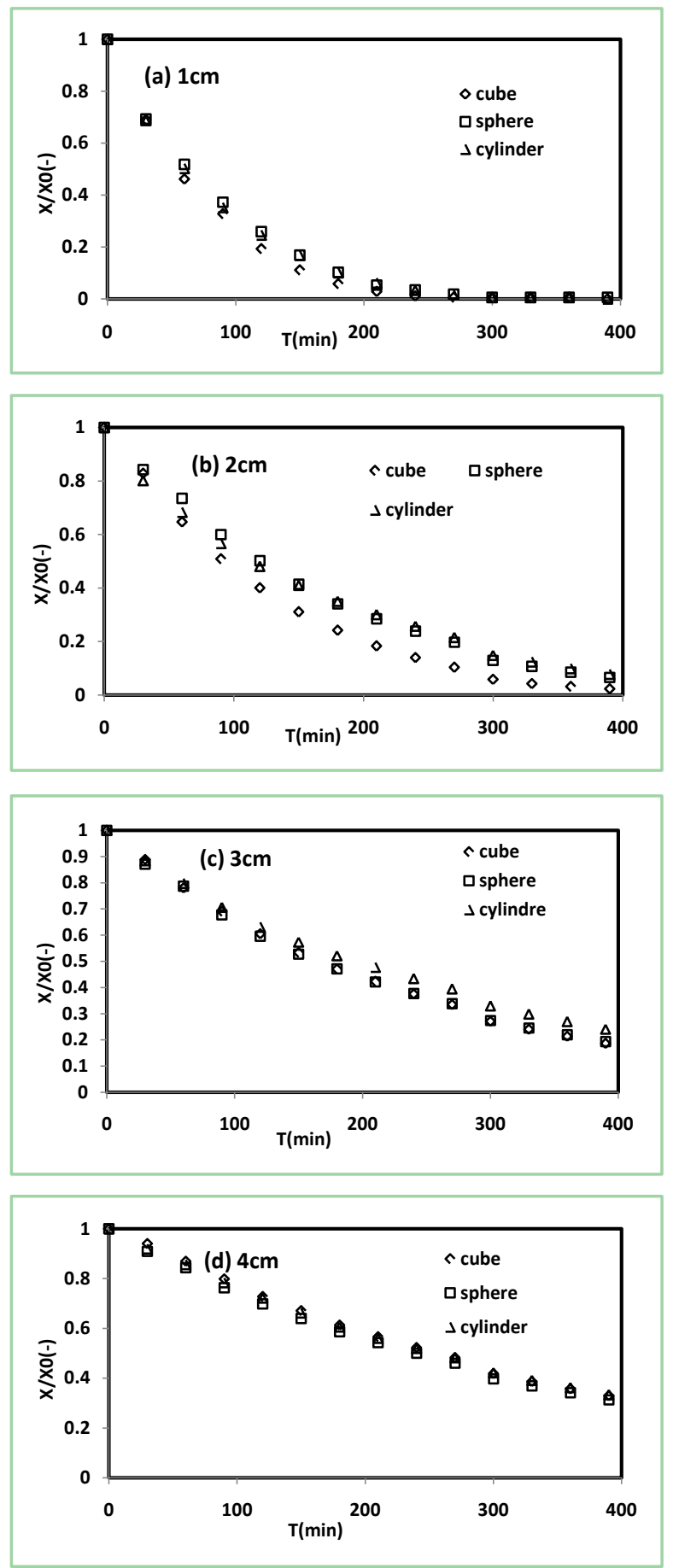

Figure 4. Influence of the initial shape on convective drying, $\mathrm{T}=80^{\circ} \mathrm{C}$, cubes, spheres, cylinders of sweet potatoes. (a) $1 \mathrm{~cm}$ edge cubes, $1 \mathrm{~cm}$ diameter spheres and $1 \times 1 \mathrm{~cm}$ cylinders; (b) $2 \mathrm{~cm}$ edge cubes, $2 \mathrm{~cm}$ diameter spheres and $2 \times 2 \mathrm{~cm}$ cylinders; (c) $3 \mathrm{~cm}$ edge cubes, $3 \mathrm{~cm}$ diameter spheres and $3 \times 3 \mathrm{~cm}$ cylinders; (d) $4 \mathrm{~cm}$ edge cubes, $4 \mathrm{~cm}$ diameter spheres and $4 \times 4 \mathrm{~cm}$ cylinders. 
We compare the state of the drying process with samples of different shapes undergoing the same drying conditions. These samples have similar sizes in order to avoid the influence of the size parameter, or form factor.

Thus, samples of cubic shapes $1 \mathrm{~cm}$ of edges, spherical of diameter $1 \mathrm{~cm}, \mathrm{cy}-$ lindrical of diameter-height $1 \mathrm{~cm} \times 1 \mathrm{~cm}$ have slightly different behaviors.

Likewise, the samples with the respective dimensions $2 \mathrm{~cm}$ edge, $2 \mathrm{~cm} \times 2 \mathrm{~cm}$ in diameter-height and $2 \mathrm{~cm}$ in diameter behave with a slight behavior,

It is the same for the other dimensions, namely $3 \mathrm{~cm}$, and $4 \mathrm{~cm}$ as an order of magnitude as a dimension

In short, if we set the size parameter, samples of different shape have a similar behavior, with a slight advantage for the cube, which has the lowest resistance to mass transfer. This difference is of the order of $0.1 \mathrm{~kg} / \mathrm{Kg}$ of water content between the cube and the spherical shape obtained after $250 \mathrm{~min}$ of drying time, for the dimensions of $2 \mathrm{~cm}$

Between the cylindrical and spherical shape, the cylindrical shape has a drying advantage. The maximum difference observed is of the order of $0.01 \mathrm{~kg} / \mathrm{kg}$ of water obtained after $150 \mathrm{~min}$ of drying time, for dimensions of $1 \mathrm{~cm}$.

\section{Conclusions}

The results obtained during the convective drying of samples of potatoes of various sizes and shapes reveal the importance of taking these dimensions into account during their drying.

For the different shapes used, the results show that the small samples are less resistant to water transfer during drying. For the cubic form, a 50\% decrease in water content was obtained after 50 minutes of drying for the dimension of $1 \mathrm{~cm}$ against, $10 \%$ decrease in its water content of the sample at $4 \mathrm{~cm}$ of edge. The difference is therefore $40 \%$.

Similar results were obtained for the other forms thus confirming the importance of the role of size in the evaluation of the drying of organic products.

For this present work, which examines samples of different shapes but with similar dimensions, it appears that for the same characteristic dimension, shape does not seem to be an important parameter. Thus, cubic, spherical or cylindrical samples dry almost identically if they have the same characteristic dimension: edge for the cube, diameter for the sphere and height-diameter for the cylinder shape.

To complete this study, we would like to take into account several forms at various drying temperatures in order to better identify the role that size plays on transfers. Also, by examining the characteristic dimensions defined by Ouoba (2013) [13], we will therefore be able to better take into account these aspects of form for our next work.

We recommend that the dryers cross the temperature, shape and size parameters for optimal results of the dried product.

It would also be more advantageous to keep the dimensions as small as possi- 
ble. It would be more judicious to have a low thickness, before any process of drying agrifood products.

\section{Conflicts of Interest}

The authors declare no conflicts of interest regarding the publication of this paper.

\section{References}

[1] Kordylas, J.M. (1991) Processing and Preservation of Tropical and Subtropical Foods. Macmillan Education Ltd., London.

[2] Dissa, A.O., Desmorieux, H., Savadogo, P.W., Segda, B.G. and Koulidiati, J. (2010) Shrinkage, Porosity and Density Behaviour during Convective Drying of Spirulina. Journal of Food Engineering, 97, 410-418. https://doi.org/10.1016/j.jfoodeng.2009.10.036

[3] Sablani, S., Rahman, S. and Al-Habsi, N. (2000) Moisture Diffusivity in Foods an Overview. In: Mujumdar, A.S., Ed., Drying Technology in Agriculture and Food Sciences Enfield, Science Publishers, Plymouth, 35-59.

[4] Hashemi, G., Mowla, D. and Kazemeini, M. (2009) Moisture Diffusivity and Shrinkage of Broad Beans during Bulk Dryin in an Inert Medium Fluidized Bed Dryer Assisted by Dielectric Heating. Journal of Food and Engineering, 92, 331-338. https://doi.org/10.1016/j.jfoodeng.2008.12.004

[5] Roberts, J.S., Tong, C.H. and Lund, D.B. (2002) Drying Kinetics and Time-Temperature Distribution of Pregelatinized Bread. Journal of Food Science, 67, 1080 1087. https://doi.org/10.1111/j.1365-2621.2002.tb09456.x

[6] Saravacos, G.D. and Maroulis, Z.B. (2001) Transport Properties of Foods. Marcel Dekker, New York. https://doi.org/10.1201/9781482271010

[7] Rovedo, C.O., Suarez, C. and Viollaz, P.E. (1995) Drying of Foods: Evaluation of a Drying Model. Journal of Food Engineering, 26, 1-12. https://doi.org/10.1016/0260-8774(94)00037-A

[8] Crank, J. (1975) The Mathematics of Diffusion. Second Edition, Oxford University Press, London, 69-88.

[9] Hassini, L., Azzouz, S., Peczalski, R. and Belghith, A. (2007) Estimation of Potato Moisture Diffusivity from Convective Drying Kinetics with Correction for Shrinkage. Journal of Food Engineering, 79, 47-56. https://doi.org/10.1016/j.jfoodeng.2006.01.025

[10] Jason, A.C. (1958) A Study of Evaporation and Diffusion Processes in the Drying of Fish Muscle. In: Fundamental Aspects of Dehydration of Foodstuffs, Society of Chemical Industry, London, 103-135.

[11] Ouoba, K.H., Zougmoré, F., Sam, R., Toguyeni, A. and Desmorieux, H. (2014) Characterization of Okra Convective Drying, Influence of Maturity. Food and $\mathrm{Nu}$ trition Sciences, 5, 590-597. https://doi.org/10.4236/fns.2014.56069

[12] Honoré, O.K., Hélène, D. and François, Z. (2019) What Process Optimizes Convective Drying of Farm Products with Complex Constitution: Case of Okra (Abelmoschus esculentus). Journal of Agricultural Chemistry and Environment, 8, 14-22. https://doi.org/10.4236/jacen.2019.81002

[13] Ouoba, K.H. (2013) Séchage des produits agroalimentaires: Influence de la taille, de la forme et de la découpe. These of Doctorate, University of Ouagadougou, Burkina 
Faso.

[14] Prabhanjan, D.G., Ramaswamay, H.S. and Raghavan, G.S.V. (1995) Microwave Assisted Air-Drying of Thin Layer Carrots. Journal of Food Engineering, 25, 283-293. https://doi.org/10.1016/0260-8774(94)00031-4

[15] Nadeau, J.P. and Puiggali, J.R. (1995) Séchage: Des processus physiques aux procédés industriels. Tec \& Doc Lavoisier, Paris.

[16] Honoré, O.K., Francois, Z. and Hélène, D. (2019) Effect of Farm Product Intrinsic Properties on Convective Drying: Case of Okra. American Journal of Plant Sciences, 10, 101-110. https://doi.org/10.4236/ajps.2019.101009

[17] Abdou-Salam, G., Honore, O. and François, Z. (2020) Taking into Account the Complex Nature and the Intrinsic Parameters of Agro-Food. Journal of Biophysical Chemistry, 11, 1-13. https://doi.org/10.4236/jbpc.2020.111001

[18] Ouoba, K.H., Zougmore, F. and Desmorieux, H. (2018) Effect of Initial Size and Shape Importance on Masse Transfer during Convective Drying. Food and Nutrition Sciences, 9, 1514-1524. https://doi.org/10.4236/fns.2018.912109

[19] Ahouannou, C. (2001) Etude du séchage de produits agroalimentaires tropicaux: Cas du manioc, du piments. Thèse de doctort, Université Nationale de Bénin.

[20] Villa-Corrales, L., Flores-Prieto, J.J., Xamán-Villaseñor, J.P. and García-Hernández, E. (2010) Numerical and Experimental Analysis of Heat and Moisture Transfer during Drying of Ataulfo Mango. Journal of Food Engineering, 98, 198-206. https://doi.org/10.1016/j.jfoodeng.2009.12.026

[21] Perré, P. and May, B. (2002) The Importance of Considering Exchange Surface Area Reduction to Exhibit a Constant Drying Flux Period in Foodstuffs. Journal of Food Engineering, 54, 271-282. https://doi.org/10.1016/S0260-8774(01)00213-8

[22] Perré, P. and May, B. (2007) The Existence of a First Drying Stage for Potato Proved by Two Independent Methods. Journal of Food Engineering, 78, 1134-1140. https://doi.org/10.1016/j.jfoodeng.2005.12.025

[23] Rapusas, R.S. and Driscoll, R.H. (1995) The Thin-Layer Characteristics of White Onion Slices. Drying Technology, 13, 1905-1928.

https://doi.org/10.1080/07373939508917056 